\title{
Induction of antibacterial proteins and peptides in the coprophilous mushroom Coprinopsis cinerea in response to bacteria
}

\author{
Anja Kombrink ${ }^{1} \cdot$ Annageldi Tayyrov $^{1} \cdot$ Andreas Essig $^{1} \cdot$ Martina Stöckli ${ }^{1,2} \cdot$ Sebastian Micheller ${ }^{1} \cdot$ John Hintze $^{1,3}$. \\ Yasemin van Heuvel ${ }^{1} \cdot$ Natalia Dürig $^{1} \cdot$ Chia-wei Lin $^{1} \cdot$ Pauli T. Kallio ${ }^{1} \cdot$ Markus Aebi $^{1} \cdot$ Markus Künzler $\mathbb{B}^{1}$
}

Received: 12 January 2018 / Revised: 23 August 2018 / Accepted: 25 September 2018 / Published online: 9 October 2018

(c) The Author(s) 2018. This article is published with open access

\begin{abstract}
Bacteria are the main nutritional competitors of saprophytic fungi during colonization of their ecological niches. This competition involves the mutual secretion of antimicrobials that kill or inhibit the growth of the competitor. Over the last years it has been demonstrated that fungi respond to the presence of bacteria with changes of their transcriptome, but the significance of these changes with respect to competition for nutrients is not clear as functional proof of the antibacterial activity of the induced gene products is often lacking. Here, we report the genome-wide transcriptional response of the coprophilous mushroom Coprinopsis cinerea to the bacteria Bacillus subtilis and Escherichia coli. The genes induced upon co-cultivation with each bacterium were highly overlapping, suggesting that the fungus uses a similar arsenal of effectors against Gram-positive and -negative bacteria. Intriguingly, the induced genes appeare to encode predominantly secreted peptides and proteins with predicted antibacterial activities, which was validated by comparative proteomics of the $C$. cinerea secretome. Induced members of two putative antibacterial peptide and protein families in $C$. cinerea, the cysteinestabilized $\alpha \beta$-defensins (Cs $\alpha \beta$-defensins) and the GH24-type lysozymes, were purified, and their antibacterial activity was confirmed. These results provide compelling evidence that fungi are able to recognize the presence of bacteria and respond with the expression of an arsenal of secreted antibacterial peptides and proteins.
\end{abstract}

\section{Introduction}

Interactions between fungi and bacteria occur in many ecological contexts and can range from mutualistic to antagonistic [1,2]. As fungi and bacteria are the main

These authors contributed equally: Anja Kombrink, Annageldi

Tayyrov, Andreas Essig

Electronic supplementary material The online version of this article (https://doi.org/10.1038/s41396-018-0293-8) contains supplementary material, which is available to authorized users.

$\triangle$ Markus Künzler

mkuenzle@ethz.ch

1 Department of Biology, Institute of Microbiology, ETH Zürich, Vladimir-Prelog-Weg 4, CH-8093 Zürich, Switzerland

2 Present address: rqmicro AG, Brandstrasse 24, 8952 Schlieren, Switzerland

3 Present address: Department of Cellular and Molecular Medicine, The Panum Institute, University of Copenhagen, Blegdamsvej 3, DK-2200 Copenhagen, Denmark decomposers of plant-derived dead organic matter, they are competitors for nutrients in such niches [3, 4]. Fungi defend their niche mainly chemically i.e., by production and secretion of antibacterials [5]. Such defense effectors range from secondary metabolites (natural products) to peptides and proteins and are not essential for the viability of the fungus under axenic conditions [6-8]. It is well established that the biosynthesis of these compounds in fungi is regulated in response to external and internal signals but the significance and the molecular mechanisms of this regulation are not well understood [9]. A deeper understanding of these issues will help to explore the hidden arsenal of fungal defense effectors e.g., for the discovery of new antibiotics [10-12].

In plants, whose primary defense is also chemical, the productions of defense effectors is either developmentally regulated, leading to tissue-specific expression patterns, or induced upon challenge with antagonists [13]. Whereas developmental regulation is thought to provide specific tissues with preventive protection against the most abundant antagonists, inducible defense enables the plant to save resources by omitting the production of defense effector 
molecules in the absence of antagonists and by tailoring its defense to a specific type of antagonist. Such an inducible defense system requires specific receptors for recognition of and differentiation between different antagonists and signaling pathways downstream of these receptors leading to transcriptional activation of genes coding for defense effectors against the respective antagonist [14].

Tissue-specific production has been reported for fungal defense effectors. For example, production of a Cs $\alpha \beta$ defensin, which is mainly active against Gram-positive bacteria, and two isolactonases cleaving typical quorum sensing molecules of Gram-negative bacteria, is restricted to vegetative mycelium and does not occur in the fruiting bodies of axenically cultivated mushroom Coprinopsis cinerea $[15,16]$. Conversely, various genes coding for nematotoxic lectins and insecticidal protease inhibitors are preferentially expressed in the fruiting body of $C$. cinerea and many other mushrooms [17, 18]. The expression pattern of these defense effectors is in accordance with the ecology of $C$. cinerea, as the vegetative mycelium of this coprophilous fungus is mainly exposed to bacterial competitors and parasites, whereas the fruiting bodies are mainly under attack of animal predators [8]. In addition to this constitutive defense of specific tissues, there is increasing evidence that fungi are also able to respond to the presence of specific antagonists through the upregulation of respective defense effectors. For example, upon challenge of the vegetative mycelium with a fungivorous nematode, $C$. cinerea induced the production of nematotoxic lectins that were not produced under axenic conditions or upon challenge with bacteria under the same condition $[19,20]$. While these studies lack the experimental evidence that this response is physiologically significant for the fungus, other studies show that upregulation of secondary metabolite biosynthesis in the mold Aspergillus nidulans in response to grazing by a soil arthropod leads to deterrence of the arthropod [21, 22]. These results suggest that fungi are able to respond to animal predators by mounting specific defense responses that directly affect the antagonist and are involved in securing fungal growth and propagation. Thus far, experimental evidence for an analogous, specific fungal defense response against bacterial competitors is poor. Although various interaction studies between fungi and bacteria report the induced expression of fungal genes coding for secondary metabolites and other putative defense effectors, the produced molecules either have not been characterized for antibacterial activity or did not show activity in such assays [23-30]. The most compelling evidence for a specific defense response of fungi against bacteria comes from two recent reports on the induced production of antibacterial depsipeptides, in the marinederived mold Emericella sp. upon cocultivation with a marine actinomycete [31] and in the fungal endophyte
Fusarium tricinctum upon cocultivation with B. subtilis [32]. These studies do not include any analysis of fungal gene expression, however.

In this study, we confronted the coprophilous model fungus $C$. cinerea with the Gram-negative and Grampositive model bacteria, Escherichia coli and Bacillus subtilis, respectively, in a previously employed semiliquid setup [15]. We investigated the response of the fungus to the bacteria through comparative transcriptomics, as well as comparative proteomics of the secretome. Analysis of the differentially expressed $C$. cinerea genes upon exposure to either of the bacteria revealed an overlapping set of highly induced genes. In line with a putative role in the extracellular interaction with bacteria, an overrepresentation of genes coding for secreted proteins was found among these induced genes. Moreover, for many induced genes, putative antibacterial activity could be attributed to the encoded proteins based on the in silico identification of conserved domains. These proteins included a paralog of the previously identified $C s \alpha \beta$-defensin Copsin, as well as members of a yet uncharacterized family of proteins containing a conserved defensin-like domain linked to a GH24-type lysozyme (phage lysozyme) domain [15, 33]. Importantly, the predicted antibacterial function of these proteins could be confirmed and characterized through antibacterial assays using heterologously produced proteins. Altogether, the presented results provide evidence for the presence of an inducible defense mechanism in C. cinerea against Gram-negative and Gram-positive bacteria.

\section{Materials and Methods}

\section{Strains, culture media and chemicals}

C. cinerea AmutBmut (A43mut B43mut pab1.2) [34] and Pichia pastoris (NRRLY11430) were used for all experiments involving a fungus. E. coli (Nissle 1917) and $B$. subtilis (NCIB 3610) [35] were used as model bacterial competitors. E. coli (DH5 $\alpha$ ) was used for cloning purposes throughout this study. C. cinerea was cultivated on YMG $(0.4 \%(\mathrm{w} / \mathrm{v})$ yeast extract (Oxoid), $1 \%(\mathrm{w} / \mathrm{v})$ malt extract (Oxoid), $0.4 \%(\mathrm{w} / \mathrm{v})$ glucose, $1.5 \%$ (w/v) agar), P. pastoris on YPD $(1 \%(\mathrm{w} / \mathrm{v})$ yeast extract, $2 \%(\mathrm{w} / \mathrm{v})$ bacteriological peptone (Oxoid), 2\% (w/v) glucose, $1.5 \%(\mathrm{w} / \mathrm{v})$ agar) and the bacteria on Luria Bertani (LB) agar plates $(0.5 \%(\mathrm{w} / \mathrm{v})$ yeast extract, $1.0 \%(\mathrm{w} / \mathrm{v})$ tryptone, $0.5 \%(\mathrm{w} / \mathrm{v})$ sodium chloride, $1.5 \%(\mathrm{w} / \mathrm{v})$ agar). Transformants of P. pastoris and $E$. coli $\mathrm{DH} 5 \alpha$ were selected and maintained on media containing either $100 \mathrm{mg} / \mathrm{l}$ or $30 \mathrm{mg} / \mathrm{l}$ of Zeocin (LabForce), respectively. The bacterial strains used for the antibacterial 
activity assays and their specific cultivation conditions are mentioned below. If not mentioned otherwise, all chemicals were bought at the highest available purity from SigmaAldrich.

\section{C. cinerea co-cultivation with bacteria and preparation of RNA}

Fungal-bacterial co-cultivation on glass beads was performed as previously described [15]. In brief, the bottom of a Petri dish $(10 \mathrm{~cm}$ diameter) was covered with borosilicate glass beads ( $5 \mathrm{~mm}$ diameter), submerged in $12 \mathrm{~mL} C$. cinerea minimal medium (CCMM). Three plugs were cut from the margin of a $C$. cinerea mycelial colony, that had been previously cultivated on YMG agar plates at $28^{\circ} \mathrm{C}$ for 3 days, and placed on top of glass beads. The fungal cultures were incubated in a humid chamber at $28^{\circ} \mathrm{C}$ for 2.5 days in the dark. E. coli Nissle 1917 and B. subtilis NCIB 3610 [35], precultivated on LB agar plates, were cultivated in CCMM liquid medium to an optical density $\left(\mathrm{OD}_{600}\right)$ of 0.3 . The cells were collected by centrifugation to remove the culture medium, resuspended in $0,5 \mathrm{ml}$ culture medium taken from the individual $C$. cinerea plates and added to the respective $C$. cinerea glass beads plates at an $\mathrm{OD}_{600}$ of 0.1. C. cinerea cultures were also left untreated for axenic controls.

All cultivations were performed in triplicates and incubated at $28^{\circ} \mathrm{C}$ for $8 \mathrm{~h}$ in the dark. Subsequently, the mycelium was harvested and flash frozen in liquid nitrogen. After lyophilizing the mycelium, $1 \mathrm{~mL}$ of Qiazol (Qiagen) and glass beads ( $0.5 \mathrm{~mm}$ diameter) were added and cells were lyzed using a FastPrep (Thermo Scientific) device (three cycles for $30 \mathrm{sec}$ at level $5.5 \mathrm{~m} / \mathrm{s}$ with cooling the samples for 3 min on ice in between the cycles). Total RNA was extracted using the RNeasy Lipid Tissue Mini Kit (Qiagen) according to the manufacturer's protocol.

\section{RNA library construction and sequencing}

RNA quality control and concentration were assessed using the Bioanalyzer 2100 (Agilent) and Qubit (1.0) fluorometer (Life Technologies), respectively. Transcriptome library preparation (TruSeq Stranded RNA Kit), cDNA sequencing (Illumina HiSeq ${ }^{\mathrm{TM}}$ 2500), and data pre-processing were performed at the Functional Genomics Center Zurich (FGCZ) following manufacturers' protocols. Data analysis was performed using SUSHI [36], an NGS data analysis workflow management system developed by the FGCZ, which supports selected open source NGS data analysis packages. In detail, reads were aligned with STAR aligner [37] with the additional options (--outFilterMatchNmin 30
--outFilterMismatchNmax 5 --outFilterMismatchNoverLmax 0.05 --outFilterMultimapNmax 50) which means that at least $30 \mathrm{bp}$ matching was required, and accepted were at most 5 mismatches, and at most $5 \%$ of mismatches. Alignments were only reported for reads with less than 50 valid alignments with the genome. The $C$. cinerea AmutBmut pab1-1 genome (2013-07-19) and its annotation v1.0 (2016-09-12, filtered gene models) from the US Department of Energy (DOE) Joint Genome Institute (JGI) were used as reference [38]. Expression counts were computed using the featureCounts from the Bioconductor package subread [39]. Differential expression was computed using the DESeq2 package [40]. The RNA data is deposited in the ArrayExpress database under the accession number E-MTAB-6876.

\section{Genome-wide analysis of differential gene expression}

C. cinerea genes that displayed increased expression in the bacteria-treated samples compared to the control samples were considered significantly induced using criteria of a log 2 fold change (FC) $\geq 2$, a $P$-value $<0.005$ and a false discovery rate $<0.005$. In addition, a minimum raw reads of 10 was taken as a threshold for gene expression. The amino acid sequences encoded by the final set of 527 genes were used in conserved domain searches (CD-search NCBI) [41] and Gene Ontology (GO) database for functional annotation [42]. A smaller set of highly induced genes was selected using a cut off of a $\log 2 \mathrm{FC} \geq 4$. Their annotation was verified manually by comparing mapped reads to the predicted JGI gene models in the Integrative Genomics Viewer (IGV) [43]. The amino acid sequences of fifteen gene products were corrected and eight genes were excluded from the list due to wrong and currently not correctable (due to low read number) annotation (Supplementary Information SI2). The amino acid sequences of 108 genes and the entire C. cinerea AmutBmut proteome were investigated for the presence of predicted signal peptides by SignalP v4.1 [44], and transmembrane domains by TMHMM v.2.0 [45]. Sequences with one predicted transmembrane domain were analyzed for possible overlap with predicted signal peptides. Overrepresentation of secreted/membrane proteins encoded by induced genes vs the whole proteome was examined using the absolute numbers in a chi-square test with Yates' correction and two-sided $P$-values were obtained. An all-vs-all Blast search (NCBI) using an Evalue of 1e-06 was performed to identify proteins encoded by duplicate genes. A cut off of minimal $60 \%$ coverage for the longest of the two sequences, at least $30 \%$ identity and a minimum bit score of 50 was used. To test the significance of the relative ratios between induced $v s$ entire genome, a chi-square test was performed. 


\section{qRT-PCR analysis of specific genes}

To monitor the transcription level of specific $C$. cinerea genes, total cDNA was synthesized from total RNA (see above for extraction protocol) as described previously [17]. qRT-PCR of specific cDNAs and data analysis was performed as previously described [19] using the primers listed in Table S2.

\section{Alignment and phylogenetic analysis}

The sequences of all 6 LYS, 10 DLP proteins and 7 Copsin paralogs were manually verified and corrected, if necessary, using IGV browser [43]. All the protein sequences that were used in this study are listed in Table S1. All the alignments were performed using the ClustalW algorithm (v2.1) [46].

\section{Cloning, production and purification of Copsin and CPP2}

The codon-optimized prepro-Copsin (CPP1) insert and the native prepro-CPP2 insert were cloned into the pPICZA expression plasmid (Invitrogen) using the restriction enzymes EcoRI/SalI (Thermo Scientific) [47]. Both constructs were linearized with SacI and transformed into $P$. pastoris by electroporation as described previously [15, 48]. The standard methanol-limited fed-batch procedure was performed in a 3.61 Labfors 5 bioreactor (Infors) according to the Pichia fermentation process guidelines of Invitrogen (Thermo Scientific) and using the process parameters and feed-in strategy as described [47]. The cells were removed by centrifugation $\left(8000 \mathrm{x} \mathrm{g}, 20^{\circ} \mathrm{C}, 20 \mathrm{~min}\right)$ and the resulting supernatant was vacuum filtered $(0.22 \mu \mathrm{m}$ rapidFiltermax 500; Techno Plastic Products TPP). The solution was diluted to a conductivity of $9-11 \mathrm{mS} / \mathrm{cm}$ by adding $\mathrm{ddH}_{2} \mathrm{O}$ and the $\mathrm{pH}$ was adjusted to 7 by adding ammonium hydroxide. After vacuum filtration $(0.22 \mu \mathrm{m}$ rapid-Filtermax 500; TPP), the solution was loaded on a self-made SPSephadex cation exchange column pre-equilibrated with binding buffer A (20 mM sodium phosphate $\mathrm{pH} 7,10 \mathrm{mM}$ $\mathrm{NaCl})$. The column was washed with $17 \%$ buffer B $(20 \mathrm{mM}$ sodium phosphate $\mathrm{pH} 7,1 \mathrm{M} \mathrm{NaCl}$ ) and the peptide was eluted with $60 \%$ buffer B. The peptide elution was monitored at UV absorbance of $210 \mathrm{~nm}$ and $280 \mathrm{~nm}$. Fractions containing either the Copsin or the CCP2 peptide were pooled and concentrated in a $2 \mathrm{kDa}$ Spectra/Por dialysis membrane (Spectrum Laboratories) as previously described [15]. The concentrated eluate was dialyzed against buffer $\mathrm{C}$ ( $2 \mathrm{mM}$ sodium phosphate buffer $\mathrm{pH} 7.2,70 \mathrm{mM} \mathrm{NaCl}$ ) at $4{ }^{\circ} \mathrm{C}$ for $24 \mathrm{~h}$. After further concentration in a $6-8 \mathrm{kDa}$ Spectra/Por dialysis membrane (Spectrum Laboratories), the protein solution was again dialyzed against buffer $\mathrm{C}$. The protein concentration was determined by a Pierce BCA protein assay, according to the manufacturer's instructions (Thermo Scientific).

\section{Antimicrobial activity of Copsin and CPP2}

MIC values were determined by the microdilution broth method according to the Clinical and Laboratory Standards Institute (CLSI) guidelines with minor modifications [49]. In brief, two-fold dilution series $(0.12-64 \mu \mathrm{g} / \mathrm{mL})$ of Copsin and CPP2 were prepared in 96-well polypropylene microtiter plates in cation-adjusted Mueller-Hinton broth (CAMHB; BD Diagnostics). The tested bacteria (see Fig. 3) were grown in LB-Lennox medium to an $\mathrm{OD}_{600}$ of $0.2-0.6$ and added to the dilution series to $10^{5}-10^{6} \mathrm{cfu} / \mathrm{mL}$. For Listeria monocytogenes and Corynebacterium diphtheriae, CAMHB was supplemented with $3 \%$ laked horse blood (Oxoid). The plates were incubated at $37^{\circ} \mathrm{C}$ for $20 \mathrm{~h}$. Each strain was tested at least in duplicate. The $\mathrm{cfu} / \mathrm{mL}$ was determined by plating dilutions of the growth control on LB-Lennox agar plates.

\section{Cloning of GH24-type lysozyme genes}

cDNA from RNA of induced co-cultures was synthesized using the Transcriptor Universal cDNA Master kit (Roche) and used as template for the amplification of the DNA sequence encoding the protein of LYS1, LYS2 and LYS3 lacking the predicted signal sequences by PCR. Primers are listed in Table S2 and contained restriction sites for EcoRI at the 5' and for NotI at the 3' end. The PCR products were ligated into $P$. pastoris expression vector pPICZ $\alpha \mathrm{A}$ (Invitrogen) using the $\alpha$-factor as secretion signal. The obtained plasmid containing LYS2 was subsequently used as template for the generation of LYS2His and LYS2His $\Delta \mathrm{N}$. The polyhistidine sequence was added to the reverse primer to obtain constructs with a C-terminal His6-tag and EcoRI and NotI restriction sites were used for ligation into pPICZ $\alpha$ A. The pPICZ $\alpha$ A-LYS2His plasmid was used as template for the generation of LYS2(D131A)His by targeted mutagenesis. Briefly, overlapping forward and reverse primers were designed with a single nucleotide change that results in the required amino acid change. The full plasmid was amplified and the PCR product was digested with $D p n I$ to remove the methylated template plasmid. After on-column cleaning, the plasmid with LYS2(D131A)His was transformed into $E$. coli $\mathrm{DH} 5 \alpha$ for amplification.

\section{GH24-type lysozyme production and purification}

The GH24-type lysozyme-encoding plasmids were linearized with SacI, or for pPICZ $\alpha$ A_LYS1 with MssI (PmeI), and transformed into $P$. pastoris [15, 48]. Approved $P$. pastoris transformants were used to inoculate $10 \mathrm{ml}$ BMGY 
medium $(1 \%(\mathrm{w} / \mathrm{v})$ yeast extract, $2 \%(\mathrm{w} / \mathrm{v})$ peptone, $1.3 \%$ (w/v) YNB without amino acids (BD Diagnostics), $100 \mathrm{mM}$ potassium phosphate buffer $\mathrm{pH} 6,1 \%(\mathrm{v} / \mathrm{v})$ glycerol) and grown at $28^{\circ} \mathrm{C}$ for $24 \mathrm{~h}$ at $180 \mathrm{rpm}$. The cells were pelleted by centrifugation $(3000 \times g, 5 \mathrm{~min}$, RT (room temperature)), resuspended into a $P$. pastoris minimal medium $(1.3 \%(\mathrm{w} / \mathrm{v})$ YNB without amino acids, $100 \mathrm{mM}$ potassium phosphate buffer $\mathrm{pH} 6,0.4 \mathrm{~g} / \mathrm{mL}$ biotin, $0.5 \%$ (w/v) $\mathrm{NH} 4 \mathrm{Cl}, 1 \%$ (v/v) $\mathrm{MeOH}$ ) and cultured further for 3 days at $28^{\circ} \mathrm{C}$ and 180 rpm, during which $\mathrm{MeOH}$ was added to $1 \%$ every $12 \mathrm{~h}$.

After centrifugation $\left(3000 \times g, 10 \mathrm{~min}, 4^{\circ} \mathrm{C}\right)$, the supernatant was filter sterilized and concentrated using Vivaflow $50 \mathrm{R}$ with a $5 \mathrm{kDa}$ cut off filter membrane (Sartorius AG). For the purification of polyhistidine-tagged proteins, the concentrated medium was dialyzed in a dialysis membrane with a $2 \mathrm{kDa}$ cut off (Spectrum Laboratories) against $2 \times 4 \mathrm{~L}$ PBS at $4{ }^{\circ} \mathrm{C}$ for $24 \mathrm{~h}$. For the non-tagged proteins, the solution was dialyzed against a $20 \mathrm{mM}$ sodium phosphate $\mathrm{pH} 6.5,50 \mathrm{mM} \mathrm{NaCl}$ buffer (buffer D). His6-tagged proteins were loaded on a PBS-calibrated $\mathrm{Ni}^{2+}$-NTA agarose column (Macherey-Nagel), washed with $10 \mathrm{mM}$ imidazole and eluted with $250 \mathrm{mM}$ imidazole in PBS. The non-tagged proteins were loaded on self-made SP-Sephadex cation exchange column equilibrated with buffer $\mathrm{D}$. After washing with buffer $\mathrm{D}$, the proteins were eluted at $200 \mathrm{mM} \mathrm{NaCl}$ in $20 \mathrm{mM}$ Na-phosphate buffer $\mathrm{pH}$ 6.5. For all proteins, after elution from the column, the elution buffer was exchanged to PBS using PD-10 columns (GE Healthcare). Protein concentrations were determined using the Pierce BCA protein assay kit (Thermo Scientific).

\section{Lysozyme activity assays}

B. subtilis 168 [50], Staphylococcus aureus 113 (DSMZ 4910) and Staphylococcus carnosus 361 (DSMZ 20501) were grown in $\mathrm{LB}$ medium at $37^{\circ} \mathrm{C}$ to an $\mathrm{OD}_{600}$ of 2 . Micrococcus luteus (DSMZ 20030) was cultivated in nutrient broth (Difco, BD Diagnostics) at $28^{\circ} \mathrm{C}$ to an $\mathrm{OD}_{600}$ of 2. Cells were harvested by centrifugation $(6000 \mathrm{rpm}, 5$ min, RT), washed with $66 \mathrm{mM}$ potassium phosphate buffer $\mathrm{pH} 6.2$ and resuspended in the same buffer to an $\mathrm{OD}_{600}$ of 100 and frozen in small aliquots. Upon use, potassium phosphate buffer was added to obtain a starting $\mathrm{OD}_{600}$ of 1 and aliquots of $100 \mu \mathrm{L}$ of the cell suspension were transferred into a 96-well microtiter plate (Tissue culture test plate 96F; TPP). Lysozymes and BSA were added to a final concentration of $20 \mu \mathrm{g} / \mathrm{mL}$ in a total volume of $102 \mu \mathrm{L}$. The cells were incubated in the microplate reader (Infinite 200 PRO; Tecan), shaking (orbital, $4 \mathrm{~mm}$ amplitude) at $37^{\circ} \mathrm{C}$, and the $\mathrm{OD}_{450}$ was measured in a time interval of $5 \mathrm{~min}$, for $60 \mathrm{~min}$ (B. subtilis and M. luteus), or $120 \mathrm{~min}$ (S. aureus and S. carnosus).

\section{Results}

\section{C. cinerea responds to $E$. coli and $B$. subtilis with induction of highly overlapping gene sets}

The response of the fungus $C$. cinerea towards two different types of bacteria, Gram-positive and Gram-negative, was investigated exploiting a previously described experimental setup for cocultivation of fungi and bacteria $[15,51]$, for comparative transcriptomics and proteomics. This setup involved cultivation of $C$. cinerea strain AmutBmut vegetative mycelium on glass beads submerged in liquid minimal medium to which either the Gram-negative bacterium E. coli Nissle 1917 or the Gram-positive species B. subtilis NCIB 3610 was added. $C$. cinerea mycelium was harvested for transcriptome analysis after $8 \mathrm{~h}$ of co-cultivation, during which time the $\mathrm{OD}_{600}$ of $E$. coli increased from 0.1 at the time of bacterial inoculation, to $0.127( \pm 0.017)$. The density of $B$. subtilis cells decreased during co-cultivation, probably due to the production of Copsin [15], resulting in an average $\mathrm{OD}_{600}$ of $0.012( \pm 0.001)$ at the time of mycelial harvesting. Differential expression of annotated protein-encoding $C$. cinerea genes was assessed by comparing DESeq2 normalized read values in E. coli-exposed or B. subtilisexposed mycelium to untreated mycelium. Comparing $E$. coli-induced and B. subtilis-induced genes $(\log 2 \mathrm{FC} \geq 2$, FDR $<0.005)$ revealed that in the presence of $E$. coli, a higher number of $C$. cinerea genes (510 genes, $3.6 \%$ of the predicted proteome) were induced than in the presence of $B$. subtilis (165 genes, $1.2 \%$ of the predicted proteome) (Supplementary Information SI2). Interestingly, 90\% of the $B$. subtilis-induced genes are also induced by $E$. coli. This overlap comprises predominantly the $E$. coli-induced genes with the highest FC (Fig. S1). We selected a smaller set of highly induced genes, using a cut off of $\log 2 \mathrm{FC} \geq 4$ and FDR $<0.005$ for detailed analysis and identification and characterization of potential fungal defense genes (Supplementary Information SI2). The differential expression of five of these genes and one non-induced gene as control was confirmed by qRT-PCR (Fig. S6). Using the same cut off, $\log 2 \mathrm{FC} \geq 4$ and FDR $<0.005$, the expression of only ten and no genes was found to be downregulated in the presence of E. coli and B. subtilis, respectively. These genes were not further investigated.

\section{C. cinerea genes with induced expression in response to bacteria tend to cluster and to occur in multi-gene families}

Inspection of the genomic location of the bacteria-induced set of 108 genes $(\log 2 \mathrm{FC} \geq 4)$ revealed that many of these genes cluster. Although the incomplete assembly of the $C$. 


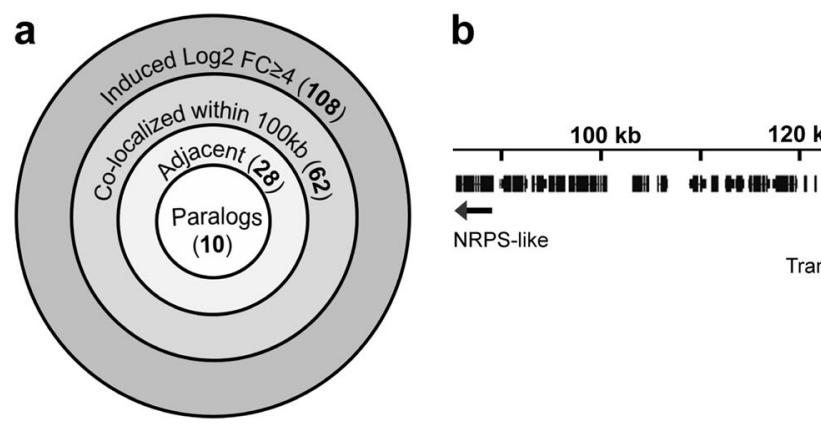

Fig. 1 Clustering of bacteria-induced genes in the C. cinerea genome. a Occurrence of different degrees of gene clustering. More than $50 \%$ of the 108 most highly induced genes were found to cluster; either within a larger chromosomal region of $100 \mathrm{~kb}$ or adjacent to each other (with a maximum of two genes in between). Paralogous genes are more likely to cluster and are therefore categorized separately. b Example illustrating the three degrees of clustering of bacteria-induced genes (marked with arrows), with the two hypothetical proteins (HPs)

cinerea AmutBmut genome makes it difficult to perform a thorough analysis, we found that 62 of the 108 induced genes colocalize with one or more other induced gene(s) within a genomic region of maximum $100 \mathrm{~kb}$. Of these 62 genes, 28 genes are located adjacent to each other or separated by a maximum of two open reading frames and 10 genes represent pairs of paralogous genes that are adjacent to each other (Fig. 1a). Clustering of bacteria-induced genes is exemplified by a $120 \mathrm{~kb}$ genomic region containing 48 protein-encodinggenes, in which six bacteria-induced genes were found (Fig. 1b). These genes encode an adenylateforming reductase [52], a ferredoxin reductase, a major facilitator superfamily (MFS) transporter, a lysozyme and two paralogous hypothetical proteins (HPs). Despite their clustering, these genes do not seem to constitute a classical gene cluster where the gene products function in the same (metabolic) pathway. Interestingly, however, we found an induced gene cluster where two bacteria-induced cytochrome P450 encoding genes flank a gene encoding a sesquiterpene synthase. The latter gene is the most highly induced gene in both $E$. coli and B. subtilis-exposed mycelium. This classical gene cluster has previously been functionally characterized and the encoded enzymes were proposed to be responsible for the production of the antimicrobial quinone sesquiterpenoid lagopodin [53].

We noticed that many bacteria-induced $C$. cinerea genes do not only cluster but also have paralogs. Since the $C$. cinerea genome is rich in gene duplications [54], we investigated whether genes belonging to multi-copy gene families would be overrepresented in the bacteria-induced gene set. In an all-versus-all blast search (NCBI) we identified 4731 out of 14242 (33\%) C. cinerea AmutBmut genes that have one or more duplicates, whereas a significant overrepresentation of 67 out of $108(62 \%)$ of the bacteriainduced genes are part of multi-gene families $(P<0.0001)$ representing paralogs with $69 \%$ amino acid sequence identity. The respective JGI protein IDs are as follows: adenylate-forming reductase, 361483; MFS transporter, 559285; GH24-type lysozyme, 442447; HPs, 442449 and 559271; Ferredoxin reductase, 361411). Notion on the dimension of the indicated numbers of (protein-encoding) genes: The $C$. cinerea genome is predicted to encode 14242 proteins according to the JGI MycoCosm (May 2018) [83]. Thus, the proteins encoded by 142 genes roughly represent $1 \%$ of the predicted proteome

(Fig. 2a and Supplementary Information SI2). In some gene families, multiple members are induced by the presence of bacteria (Fig. 2b). For example, the genome of $C$. cinerea encodes for a gene family of three adenylate-forming reductases that might be involved in secondary metabolite synthesis [52], and two of the(se) genes are induced in the presence of bacteria. Other induced genes might encode proteins that contain the same predicted conserved domain, but belong to different families (Fig. 2b) as the family classification is based on overall sequence similarity rather than the presence of a domain. For example, four induced genes encode for proteins that are all predicted to be MFS transporters but they belong to different gene families due to low sequence similarity with each other. MFS transporters may be involved in the export of antibiotics produced by $C$. cinerea or of antifungal compounds produced by bacteria out of the fungal cell [55]. Taken together, we found that bacteria-induced $C$. cinerea genes are not randomly distributed in the genome and that multi-copy genes are overrepresented.

\section{C. cinerea responds to bacteria by the secretion of proteins with predicted antibacterial activity}

Induced $C$. cinerea genes encoding secreted proteins were of particular interest, as these proteins might directly interact with bacteria and possibly possess antibacterial activity [8]. For this reason, the predicted localization of proteins, encoded by the set of the 108 most highly induced genes, was examined. A comparison with the predicted localization of all $C$. cinerea proteins revealed a significant overrepresentation of secreted proteins in the induced gene set $(P<0.0001)$ (Fig. 2c). Most of the 44 predicted secreted proteins do not contain a conserved domain (CD search, $\mathrm{NCBI}$ ), and 20 of the proteins are smaller than 250 amino 

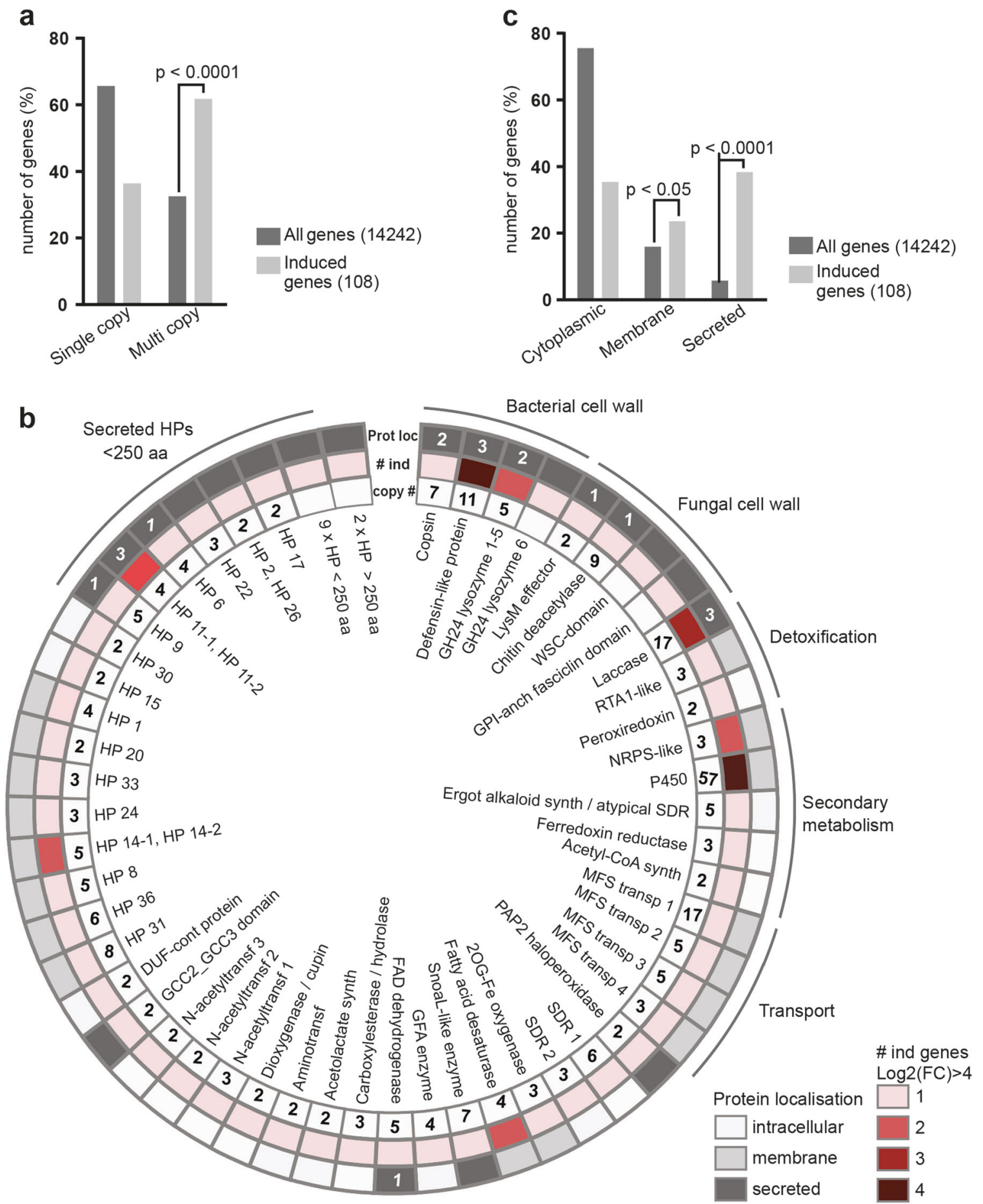

acids. These hypothetical proteins (HPs) resemble the small secreted proteins (SSP) that are produced by pathogenic and symbiotic fungi during host colonization as effectors to modulate the host and often lack homology to other proteins $[56,57]$. The induced expression of a significant number of genes coding for SSP-like proteins suggests that these proteins play a role as effectors in the interaction of $C$. cinerea with bacteria.
Interestingly, most secreted proteins containing a conserved domain (CD search NCBI) (Fig. 2b), could be assigned a putative function related to fungal or bacterial cell walls. For example, one protein (JGI protein ID, 422563) contains two Lysin motifs (LysM) and resembles LysM effectors of plant-pathogenic fungi which were demonstrated to bind fungal cell wall chitin [58]. Related to chitin is also the putative function of a chitin deacetylase 
Fig. 2 Overrepresentation of multi-copy genes and genes encoding secreted proteins among bacteria-induced genes. a Relative numbers of single copy or duplicate genes among all $C$. cinerea genes or the bacteria-induced genes with a $\log 2 \mathrm{FC} \geq 4$. b Representation of bacteria-induced genes being part of a multi-gene family and/or encoding predicted secreted proteins. Protein annotation is based on the identification of conserved domains (CD search NCBI) and putative functions related to bacterial-fungal interaction were assigned. The same annotation may occur multiple times in case multiple induced genes encode proteins with the same conserved domain but categorize in different gene families due to low overall similarity, e.g., GH24type lysozyme 1-5 and 6. For bacteria-induced multi-copy genes, the total number of genes in the gene family is indicated in the inner circle (copy \#). The colors in the second circle indicate how many genes of this family are bacteria-induced with a $\log 2 \mathrm{FC} \geq 4$ (\# ind). The predicted localization (Prot loc) of the encoded proteins is represented in the outer circle. The white numbers indicate the number of secreted proteins of the respective family that were identified in the E. coliinduced secretome. $\mathbf{c}$ Relative numbers of all $C$. cinerea proteins and the proteins encoded by bacteria-induced genes $(\log 2 \mathrm{FC} \geq 4)$ that are predicted to be cytoplasmic, membrane-bound (TMHMM2.0) or secreted (SignalP4.1). a, c $P$-values are calculated by chi-square tests using numerical values. FC fold change, HP for hypothetical protein, MFS for major facilitator superfamily, DUF for domain of unknown function, GFA for glutathione-dependent formaldehyde-activating

(JGI protein ID, 440521), likely involved in conversion of chitin to chitosan. Furthermore, three laccase encoding genes (JGI protein IDs, 502564, 208308, 488706) were found to be induced; fungal laccases have been implicated in stress protection through their involvement in melanin synthesis, but also through degradation of antifungal compounds produced by bacteria [59] (Fig. 2b). The bacterial cell wall is the likely target of $C$. cinerea proteins containing a glycoside hydrolase 24 (GH24; PFAM 00959; phage lysozyme) domain (see below). Another family of ten genes, five of which are induced by bacteria, encode small secreted proteins with a length of around 100 amino acids with a conserved pattern of twelve cysteine residues. The amino acid sequence of these proteins do not indicate a conserved domain, but homology modeling using PHYRE2 [60] predicts a defensin-like fold, consisting of an $\alpha$-helix and two antiparallel $\beta$-strands stabilized by disulfide bonds. Based on previous studies of fungal Cs $\alpha \beta$-defensins $[15,61$, 62], we hypothesize that these proteins have antibacterial activity via interactions with the bacterial cell wall and designate these $C$. cinerea proteins defensin-like peptides (DLPs). Interestingly, the bacteria-induced gene set also was found to contain a paralog of a gene that encodes for the previously characterized antibacterial Cs $\alpha \beta$-defensin Copsin [15].

To verify whether the differential transcription of genes encoding secreted proteins is also reflected on protein level, we investigated the differential (cultivated with and without bacteria) secretome of $C$. cinerea on protein level by comparative proteomics (see Supplementary information SI1 for experimental details). To this end, the proteins in the culture supernatant of $C$. cinerea axenic cultures and cocultures with $E$. coli were analyzed. Based on our analysis, a total of $23 C$. cinerea proteins were more abundant in the presence of $E$. coli compared to the control (FC $\geq 4$ ) (Fig. 2b and $\mathrm{S} 2$ ), of which 13 proteins are encoded by genes that are bacteria-induced ( $F C \geq 4)$ (Supplementary Information SI3). In addition, four more proteins (three DLPs and one chitin deacetylase) that are encoded by family members of bacteria-induced genes, are more abundant by a $\mathrm{FC} \geq 2$.

\section{Bacteria-induced member of the $C$. cinerea Csaß- defensin family has the same antibacterial activity profile as Copsin}

To investigate the role of induced secreted proteins as antibacterial defense effectors of $C$. cinerea, bacteriainduced members of the Cs $\alpha \beta$-defensin and GH24-type lysozyme families were produced in P. pastoris and the antibacterial activity of the recombinant peptides and proteins was evaluated.

We previously identified and characterized an antibacterial $C s \alpha \beta$-defensin, termed Copsin, produced by $C$. cinerea by activity-based fractionation of the fungal secretome [15]. Copsin is active against Gram-positive bacteria and targets peptidoglycan biosynthesis via binding to the lipid II precursor [47]. The production of Copsin in vegetative mycelium of $C$. cinerea was found to be constitutive i.e., not modulated by the presence of bacteria (Fig. S3A). In contrast, a Copsin paralog that was highly induced upon exposure to bacteria, was identified. This gene was found to be located adjacent to the Copsin-encoding gene and was termed Copsin-paralogous peptide 2 (cpp2). Additional BLAST search revealed that $C$. cinerea encodes for a family of 7 Copsin-paralogous peptides with a predicted Cs $\alpha \beta$ defensin fold, of which only the gene encoding for CPP2 showed induced expression upon bacterial challenge (Fig. 3a-c; Fig. S3A). Determination of the minimal inhibitory concentrations (MICs) of recombinant CPP2 revealed an antibacterial activity profile that was highly similar to the profile of Copsin (Fig. 3d). These results suggest that $C$. cinerea is able to fortify the constitutive antibacterial activity of Copsin through induced production of a Copsinparalog upon exposure to bacteria. Moreover, this finding demonstrates that the expression pattern of duplicated genes can significantly diversify while the function of the encoded proteins is preserved.

\section{Bacteria-induced members of the $C$. cinerea GH24-type lysozyme family lyse bacterial cells}

The genome of $C$. cinerea encodes for six paralogs of GH24-type lysozymes (Fig. 4, S3 and S4). The archetype of this type of lysozyme is the T4 lysozyme, also referred to as 


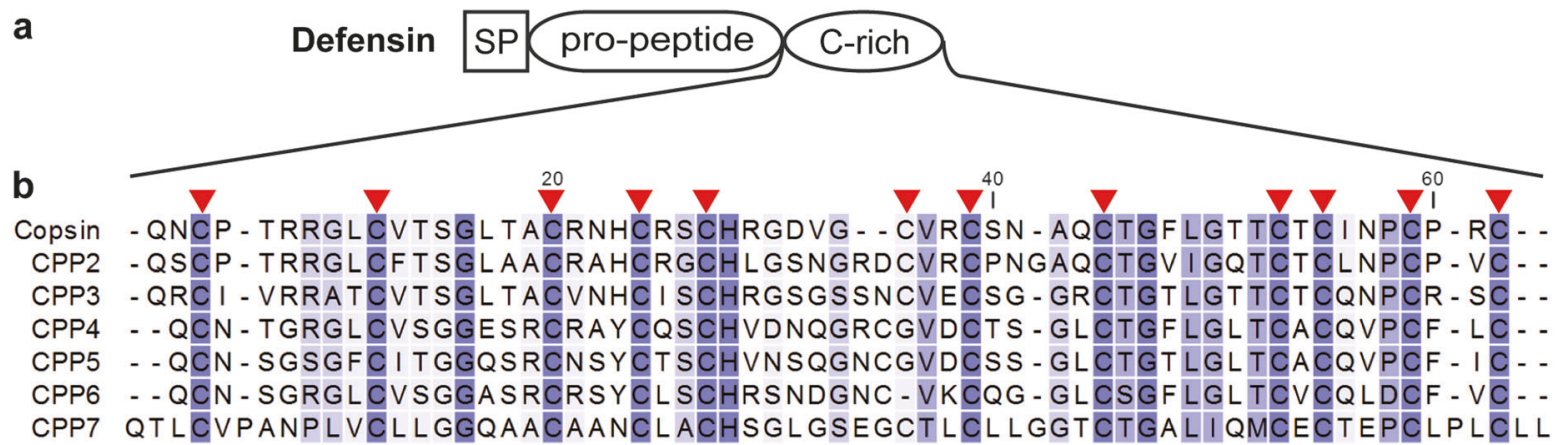

C

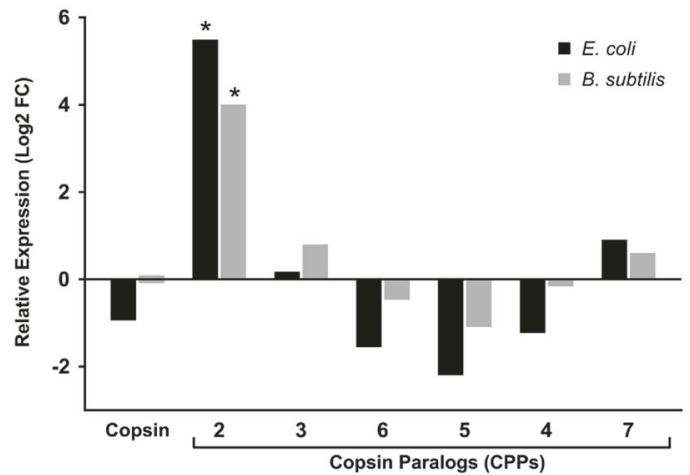

Fig. 3 Overview of Copsin-paralogous peptides (CPPs) encoded in the genome of $C$. cinerea. a Premature Copsin (CPP1) and its paralogs (CPP2-6) consist of a signal peptide (SP), a pro-peptide and a mature peptide of 57 to 65 amino acids. b The mature peptides show a conserved N-terminal glutamine and a characteristic cysteine pattern of 12 residues, which are indicated with red arrows. The sequences were aligned using the ClustalW algorithm (v2.1). c Relative expression of

phage endolysin or lysin [63, 64]. It hydrolyzes the $\beta-1,4$ glycosidic bond of peptidoglycan (PGN) in the bacterial cell wall for the release of the T4 phages [65]. The expression of three $C$. cinerea GH24-type lysozyme-encoding genes, termed lysl-3, was found to be highly induced in the presence of bacteria (Fig. 4c). In agreement with this finding, LYS1 and LYS2 were also found in the E. coli-induced secreted proteome (Supplementary Information SI3).

Alignment of the sequences of all six $C$. cinerea $\mathrm{GH} 24-$ type lysozymes revealed that five proteins contain a conserved cysteine-rich $\mathrm{N}$-terminal domain, while the $\mathrm{N}$ terminus of LYS6 is different and contains repetitive sequences (Fig. S4). Intriguingly, the amino acid sequence of this N-terminal domain, in particular the pattern of the twelve conserved Cys-residues, is homologous to the amino acid sequence of the DLPs described above and most likely adopts a defensin-like fold which is stabilized by up to six disulfide bridges (Fig. 4a and Fig. S3B). Thus, the $C$. cinerea genome encodes five GH24-type lysozymes (Table S1, LYS1-5) and ten DLPs (Table S1, DLP1-10) which share a defensin-like domain. These gene families have most likely arisen via gene fusion, multiplication and d

\begin{tabular}{l|c|c|c} 
Bacterium & DSMZ & Copsin & CPP2 \\
\hline Bacillus subtilis 168 & & $4 \mu \mathrm{g} / \mathrm{ml}$ & 2 \\
Enterococcus faecalis & 20478 & 8 & 4 \\
Enterococcus faecium vanA & 13590 & 4 & 2 \\
Staphylococcus carnosus & 20501 & 8 & $2-4$ \\
Staphylococcus aureus & 4910 & $>64$ & $>64$ \\
Escherichia coli & 1103 & $>64$ & $>64$ \\
Pseudomonas aeruginosa & 1117 & $>64$ & $>64$ \\
Listeria monocytogenes & WSLC 1042 & 1 & 2 \\
Corynebacterium diphtheriae & 44123 & 8 & 4
\end{tabular}

the genes coding for Copsin and its paralogs in the presence of $E$. coli or B. subtilis compared to the axenic control. Asterisks indicate $\log 2$ $\mathrm{FC} \geq 2$ and FDR value $<0.005$. DeSeq 2 normalized counts were placed in Fig. S3A. d Minimal inhibitory concentrations (MICs; $\mu \mathrm{g} / \mathrm{ml}$ ) of Copsin and its paralog CPP2 for different bacteria. The values were determined using to the microdilution broth method [49]

diversification. The bacteria-induced expression of several members of these gene families suggests a role of the encoded proteins and peptides in the interaction with bacteria.

In order to test the activity of defensin-like domaincontaining lysozymes against bacteria, LYS1, LYS2, and LYS3 were produced in P. pastoris, purified (Fig. S5A) and tested for their ability to lyse bacterial cells. Analogous attempts to heterologously produce DLPs or isolated defensin-like domains of the identified fungal lysozymes were not successful. For the lysis assays, stationary bacterial cells were suspended in phosphate buffer in a 96-well microtiter plate and incubated with the recombinant lysozymes. Hen egg white lysozyme (HEWL) was used as positive and bovine serum albumin (BSA) as negative control. Optical density at $450 \mathrm{~nm}$ of the suspensions was measured over 60 to $120 \mathrm{~min}$.

In case of $B$. subtilis, the three tested $C$. cinerea lysozymes showed lysis kinetics very similar to HEWL, with a rapid decrease in optical density between 10 and $20 \mathrm{~min}$ (Fig. 5a). In the assays with M. luteus (lysodeikticus), which is known for its susceptibility to lysozyme activity [66], 

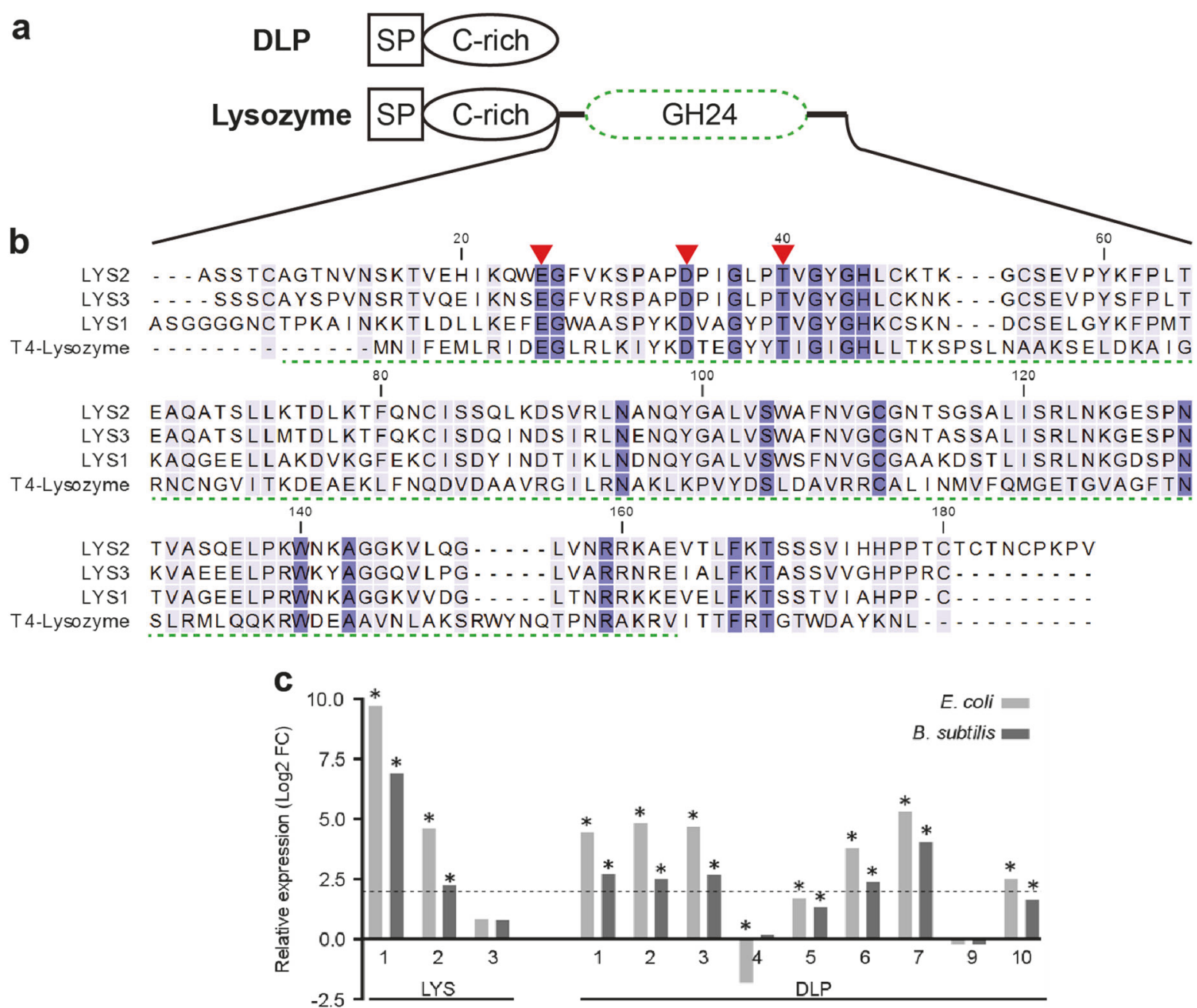

Fig. 4 C cinerea encodes a family of GH24-type lysozymes (LYS) and defensin-like peptides (DLPs). a DLPs are composed of a signal peptide (SP) and a domain enriched with 12 cysteine residues as found in copsin and paralogs (Fig. 3 and Fig. S3B). This cysteine-rich domain was also identified in secreted lysozymes, which is then attached over a linker-peptide to a C-terminal glycosyl hydrolase (GH24) domain (Fig. S3B and Fig. S4). b A sequence alignment of the lysozyme domain of LYS1-3 revealed conserved catalytic residues (red arrows) characteristic for the GH24-type lysozyme family with T4 lysozyme (PDB: 2LZM) as a founding member [33, 65]. The

LYS1 showed significantly reduced cell lysis activity compared to LYS2 and LYS3 (Fig. 5d). We further investigated this difference by incubating fluorescently labeled M. luteus cell wall preparations (EnzCheck, Thermo Scientific) with a concentration series of the lysozymes and subsequent measuring of released fluorescence due to cleavage of M. luteus PGN. In accordance with the cellbased assay, no fluorescence above background level was detected in this assay upon incubation with LYS1, whereas incubation with LYS2 and LYS3 resulted a concentrationdependent release of fluorescence (Fig. 5g). The inability of LYS1 to cleave M. luteus PGN and its drastically reduced M. luteus cell lysis activity suggested a significant alignment was performed using the ClustalW algorithm (v2.1). The GH24 domain was assigned by the BlastP algorithm according to the LYS2 sequence and is marked with a green dashed line. c Relative expression of LYS- and DLP-encoding genes in the presence of $E$. coli or $B$. subtilis compared to the expression in the axenic control as determined by RNA sequencing. The dashed line and asterisks indicate the cut off of $\log 2 \mathrm{FC} \geq 2$ and FDR value of $<0.005$, respectively. DeSeq 2 normalized counts were placed in Figure S3C. lys 4 , lys5, and $d l p 8$ are not included in the histograms due to their low level of expression ( $<10$ reads/locus)

difference in substrate specificity between this lysozyme and the other two paralogs. To further assess the lysozyme specificity for Gram-positive bacteria, we performed the bacterial cell lysis assays with Staphylococcus carnosus and S. aureus (Fig. 5c, f). In contrast to S. carnosus, S. aureus is known to O-acetylate its PGN, which contributes to resistance towards PGN cleavage by most lysozymes such as the HEWL-type [67]. Although less rapidly than observed for $M$. luteus or B. subtilis, S. carnosus cells lysed in the presence of LYS2 and LYS3, but not in the presence of LYS1. In contrast, incubation with neither of the $C$. cinerea lysozymes resulted in $S$. aureus cell lysis. Taken together, these results demonstrate that $C$. cinerea lysozymes have the 

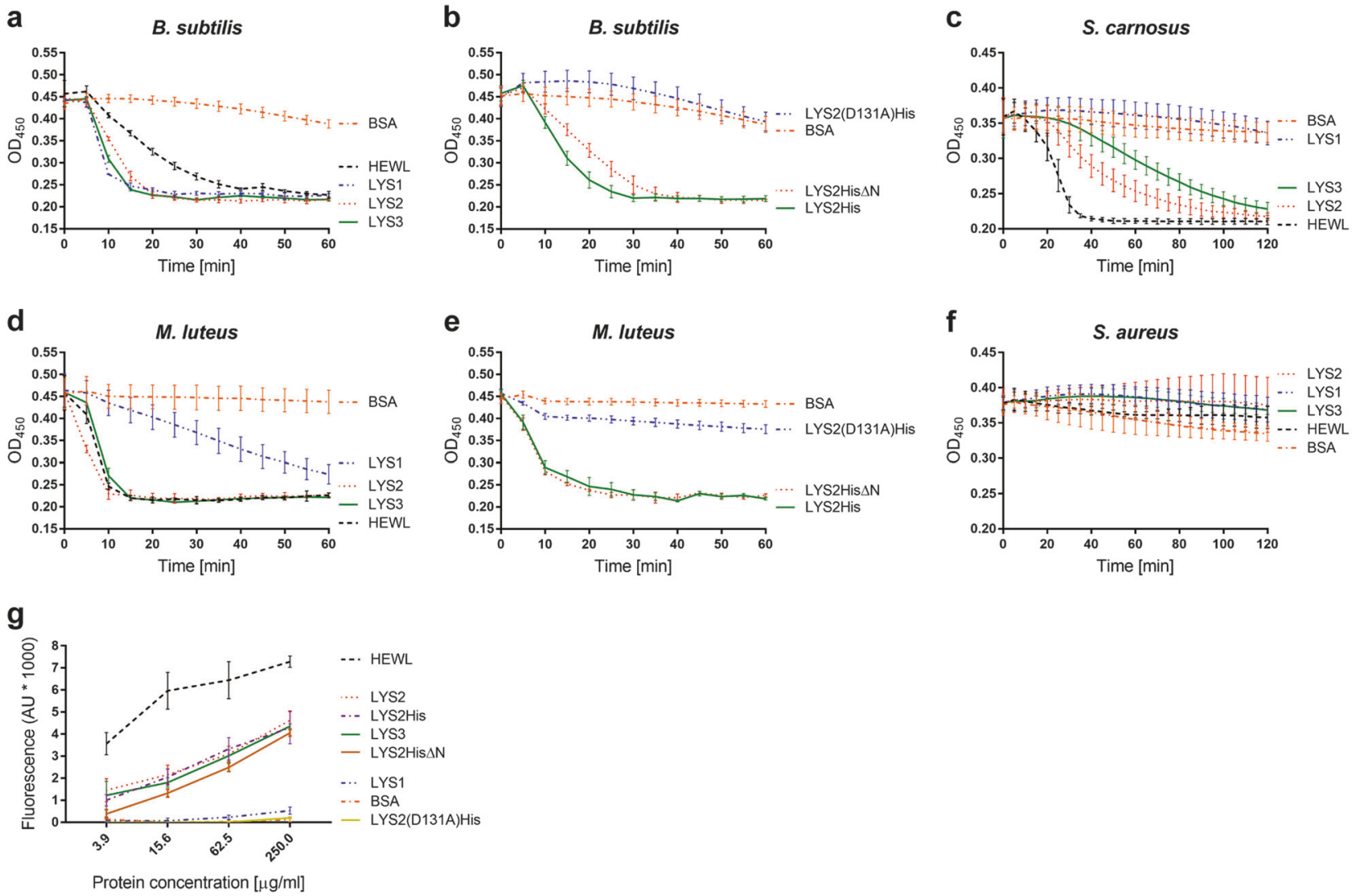

Fig. 5 Activity of $C$. cinerea GH24-type lysozymes on Gram-positive bacteria. a-f Bacterial cell lysis activity was determined in a microtiter plate turbidity assay for B. subtilis, M. luteus, S. carnosus and $S$. aureus. Cells were treated with the following proteins at a concentration of $20 \mu \mathrm{g} / \mathrm{ml}$ : Untagged recombinant lysozymes (LYS1-3), His6-tagged LYS2 (LYS2His), His6-tagged lysozyme domain of LYS2 (LYS2His $\Delta \mathrm{N}$ ), His6-tagged catalytic mutant LYS2 (LYS2 (D131A)His), hen egg white lysozyme (HEWL) as positive and bovine serum albumin (BSA) as negative control. The bacterial suspensions were incubated at $37^{\circ} \mathrm{C}$ and data points were acquired at an

optical density of $450 \mathrm{~nm}$ in $5 \mathrm{~min}$ time intervals. The average of three biological replicates is shown together with the standard deviation. $\mathbf{g}$ Lysozyme activity was determined using the EnzChek Lysozyme assay kit (Thermo Scientific). 4-fold dilution series of the proteins listed above were incubated with $M$. luteus fluorescein-labeled cell wall. The release of fluorescein due to hydrolysis of cell wall was measured after $30 \mathrm{~min}$ of incubation at $37^{\circ} \mathrm{C}$ with excitation and emission wavelengths of $485 \mathrm{~nm}$ and $535 \mathrm{~nm}$, respectively. Each data point represents the average of three replicates. Error bars indicate standard deviation

ability to lyse bacterial cells and that this activity is likely based on different modes of action on different bacterial species.

The contribution of the defensin-like domain and the predicted active site residues to the bacterial cell lysis activity of the $C$. cinerea lysozymes was assessed by producing variants of LYS2. Full-length LYS2 (LYS2His), truncated LYS2 containing only the lysozyme domain (LYS2His $\Delta \mathrm{N}$ ) and a presumptive LYS2 catalytic mutant (D131A) (Fig. S5) were produced with a C-terminal His6tag in $P$. pastoris and purified using metal chelate chromatography. LYS2His $\Delta \mathrm{N}$ lysed $B$. subtilis and M. luteus cells as efficiently as full length LYS2His (Fig. 5b, e). In contrast, the LYS2(D131A)His mutant did not cause lysis of B. subtilis or M. luteus (Fig. $5 \mathrm{~b}$, e). In agreement with these results, LYS2His and LYS2His $\Delta \mathrm{N}$ cleaved M.luteus PGN in the EnzChek lysozyme assay, whereas the LYS2
(D131A)His mutant did not (Fig. 5g). In conclusion, the results indicate that the N-terminal DLP domain of the lysozyme does not contribute to bacterial lysis and peptidoglycan hydrolysis activity of LYS2 whereas the predicted active site residue D131 was critical for these activities.

\section{Discussion}

The defense mechanisms employed by fungi to cope with competing or antagonistic bacteria are poorly understood. While fungi are notorious producers of antibacterial compounds, it is not clear whether these compounds can be produced as part of a specific defense response against bacteria. In the present study, results of transcriptome and secretome analyses demonstrate that bacteria induce an antibacterial response in the fungus $C$. cinerea. This 
response predominantly relies on secreted proteins, of which many are predicted or shown to have antibacterial activity. The majority of the secreted proteins found in the induced secretome or encoded by bacteria-induced genes are smaller than 250 amino acids and lack annotated domains, which complicates functional predictions. These characteristics are reminiscent of effector proteins that are produced by fungal pathogens and endophytes, as well as mycorrhizal fungi during plant colonization to establish fungal growth in the host [68-70]. An overrepresentation of genes encoding small secreted proteins (SSPs) was also found among $P$. anserina genes that were induced upon exposure to two bacterial Serratia species, one of which kills the fungus [26]. Therefore, it appears that the secretion of SSPs plays a significant role in the interaction of fungi with plants and bacteria, including mutualistic, pathogenic, or competitive interactions.

In previous interaction studies, the confrontation between fungi and bacteria was mostly done on agar plates, often without physical contact of the organisms $[23,24,26]$. In this study we used a semi-liquid setup, in which we cultivated $C$. cinerea on submerged glass beads $[15,51]$. This setup allowed motile bacteria, when added to the liquid phase, to interact with the mycelium in a dynamic and intimate manner. Moreover, this experimental system allowed us to analyze the gene expression of $C$. cinerea in response to bacteria on both transcriptome and secreted proteome level as secreted proteins could be easily retrieved from the liquid phase. These analyses revealed a relatively large number of genes with a high level of induction under these conditions.

Many of the bacteria-induced genes in the genome of $C$. cinerea are clustered. On the one hand, this is explained by tandem gene duplications. Gene duplication resulting in expansion of (effector) gene families has been described for fungal pathogens and may facilitate evolution of new protein functions due to functional redundancy [71, 72]. One prominent example is the bacteria-induced gene cpp 2 which is localized next to the paralogous gene $c p p l$ coding for the previously described antibacterial Cs $\alpha \beta$-defensin Copsin [15]. On the other hand, clustering of non-homologous but functionally related genes is known from secondary metabolite biosynthesis in fungi [73]. It is hypothesized that clustering minimizes meiotic recombination between and/or facilitates coregulation of these genes [74, 75]. The above mentioned example of the cpp2 and cpp1 gene tandem, however, shows that duplicated genes can differ considerably in their expression pattern since $c p p 1$ is expressed constitutively under the applied conditions. Since CPP2 and Copsin are functionally redundant regarding their antibacterial activity, this special regulation pattern implies a mechanism where a Cs $\alpha \beta$-defensin-mediated, constitutive defense of $C$. cinerea against bacteria is fortified in response to bacterial challenge. Genes coding for $\operatorname{Cs} \alpha \beta$ defensins (of different classes) have recently been identified in a wide range of fungal genomes and, based on characterized antibacterial activities thus far, might be part of a general defense of fungi against bacteria [61, 62, 76-78]. Accordingly, structural modeling predicts additional defensin-like proteins among our set of bacteria-induced, non-annotated C. cinerea proteins. These predictions are currently tested by heterologous expression of these proteins and analysis of their structure and function.

Bacteria-induced genes in C. cinerea also tend to belong to expanded gene families. This phenomenon is exemplified by the identification of a family of Copsin paralogs in $C$. cinerea (Fig. 3). Other examples are two families of $C$. cinerea proteins containing a defensin-like domain, either as single domain in defensin-like proteins (DLPs) or Nterminal of a GH24-type lysozyme domain. Both DLPs and GH24-type lysozymes are encoded by expanded gene families of ten and five genes, respectively. Detailed analysis of the expression and the function of individual family members suggests that these proteins play a significant role in the interaction with bacteria. Lysozymes with a GH24 domain belong to the phage lysozyme family and supposedly have muramidase activity, i.e., hydrolysis of the glycosidic bond between GlcNAc and MurNAc [79]. Despite the predicted muramidase activity, heterologously produced $C$. cinerea LYS1 was, in contrast to LYS2 and LYS3, not able to hydrolyze fluorescently labeled $M$. luteus cell wall material (Fig. 5g). In agreement with this observation, LYS1 was also less efficient in lysing M. luteus (Fig. 5d) and failed to lyse S. carnosus cells (Fig. 5c). These differences in activity suggests that $C$. cinerea lysozymes have functionally diverged. The activity of LYS2 appears to be dependent on its enzymatic function as mutation of the predicted active site residue (D131A) abolishes all activities (Fig. 5b, e, g). In addition, the cell lysis activity of the three $C$. cinerea lysozymes appears to be dependent on the acetylation of PGN since $S$. aureus cells could not be lysed by any of the analyzed recombinant proteins (Fig. 5f). The function of the defensin-like domain of the lysozymes remains unclear as deletion of this domain did not have a significant effect on the activity of LYS2 in the cell lysis or cell wall material hydrolysis assays (Fig. 5b, e, g). Although we could not assess the antibacterial activity of the DLPs, the identification of four $d l p s$ in bacteria-induced transcriptome and three DLPs in the E. coli-induced secretome strongly suggests that these proteins play a significant role in the interaction of $C$. cinerea with bacteria. To our knowledge, there is no precedence for such a dual appearance of a defensin-like domain in any organism. Conversely, although the distribution of proteins that consist of a defensin-like domain fused to a lysozyme domain is restricted to a few fungal species, the occurrence of the 
GH24-type lysozyme domain is widespread in the fungal kingdom. Therefore, it is hypothesized that, in other fungal species, proteins with similar (catalytic) functions as the characterized $C$. cinerea LYS proteins, but with a different domain organization, play a similar role in antibacterial defense.

The overlap between the induced $C$. cinerea genes upon challenge with either Gram negative E. coli or Gram positive $B$. subtilis was particularly evident among the most highly induced genes. Overlapping responses of the fungal plant pathogenic basidiomycete Rhizoctonia solani, as well as of the coprophilous ascomycete Podospora anserina to bacterial Serratia species of different levels of antagonism, were reported recently $[24,26]$. These results suggest that fungi do not differentiate between different bacteria and mount a rather general defense response that leads to the secretion of an arsenal of molecules affecting the growth of different types of bacteria e.g., by targeting conserved bacterial structures. Accordingly, two of the characterized defense effectors, Cs $\alpha \beta$-defensins and GH24-type lysozymes fused to a defensin-like domain, affect peptidoglycan, a conserved constituent of the bacterial cell wall. The induction of genes with putative antifungal functions (LysM, chitinase, chitin deacetylase) in this study may indicate though that the fungus cannot differentiate between bacteria and fungi. Despite the apparent lack of specificity of the fungal defense response with regard to different types of microbial competitors, the lack of significant overlap between the transcriptional response of $C$. cinerea to fungivorous nematodes and to bacterial competitors on agar plates [19] suggests that this fungus is able to discriminate between these two types of antagonists and to induce an antagonist-specific transcriptional response. It is currently not clear, however, how widespread this capability is in the fungal kingdom. Also the physiological significance of the antibacterial response of the fungus upon bacterial challenge is not clear since the fungus could use the secreted antibacterial proteins either as defense molecules to protect itself from damage or as predatory molecules to gain additional nutrients.

The molecular basis of the antagonist-specific responses of the fungus is currently unknown. Future experiments will address the questions whether the antibacterial response of C. cinerea is elicited by a single or multiple signals, whether the signal(s) is(are) of bacterial or fungal (produced by bacterial enzymes) origin, whether the signal(s) is (are) on the surface of the microbial cells or shed into the culture supernatant and, finally, whether Gram-positive and Gramnegative bacteria are recognized via the same signal(s) and respective fungal receptor(s) or whether specific recognition pathways exist that lead to activation of the same response. Candidate microbe-associated molecular patterns (MAMPs) that are common between the two types of bacteria, are peptidoglycan fragments (muropeptides). These compounds have been shown to be steadily shed into the medium during bacterial growth and to elicit responses in bacteria, animals and plants and even fungi via cell surface or intracellular receptors [80, 81]. Comparative genomics suggests that fungi lack cell surface Toll-Like Receptors (TLRs) and rely entirely on intracellular Nucleotide oligomerization domain-Like Receptors (NLRs) for defense [82]. The experimental evidence for this hypothesis, however, is rather weak so far and it remains to be seen whether the antibacterial response of $C$. cinerea is mediated via such receptors. Elucidation of these molecular details will help to advance the general knowledge about the innate defense system of fungi which lags far behind the one of plants and animals.

Acknowledgements We would like to thank the Functional Genomics Center Zürich, in particular Dr. Weihong Qi, for technical support. We are grateful to Dr. Andrea Sánchez-Vallet for proofreading and discussions and to Dr. Jerome Collemare for technical assistance and proofreading. This work was supported by ETH Zürich (ETH Zürich Postdoctoral Fellowship to A.K. and Grant ETH-45 16-1) and the Swiss National Science Foundation (Grant 31003A_149512).

\section{Compliance with ethical standards}

Conflict of interest The authors declare that they have no conflict of interest.

Open Access This article is licensed under a Creative Commons Attribution-NonCommercial-ShareAlike 4.0 International License, which permits any non-commercial use, sharing, adaptation, distribution and reproduction in any medium or format, as long as you give appropriate credit to the original author(s) and the source, provide a link to the Creative Commons license, and indicate if changes were made. If you remix, transform, or build upon this article or a part thereof, you must distribute your contributions under the same license as the original. The images or other third party material in this article are included in the article's Creative Commons license, unless indicated otherwise in a credit line to the material. If material is not included in the article's Creative Commons license and your intended use is not permitted by statutory regulation or exceeds the permitted use, you will need to obtain permission directly from the copyright holder. To view a copy of this license, visit http://creativecommons. org/licenses/by-nc-sa/4.0/.

\section{References}

1. Deveau A, Bonito G, Uehling J, Paoletti M, Becker M, Bindschedler $\mathrm{S}$, et al. Bacterial-fungal interactions: ecology, mechanisms and challenges. FEMS Microbiol Rev. 2018;42:335-52.

2. Frey-Klett P, Burlinson P, Deveau A, Barret M, Tarkka M, Sarniguet A. Bacterial-fungal interactions: hyphens between agricultural, clinical, environmental, and food microbiologists. Microbiol Mol Biol Rev. 2011;75:583-609.

3. Moller J, Miller M, Kjoller A. Fungal-bacterial interaction on beech leaves: influence on decomposition and dissolved organic carbon quality. Soil Biol Biochem. 1999;31:367-74.

4. Rousk J, Baath E. Growth of saprotrophic fungi and bacteria in soil. FEMS Microbiol Ecol. 2011;78:17-30. 
5. Boer W, Folman LB, Summerbell RC, Boddy L. Living in a fungal world: impact of fungi on soil bacterial niche development. FEMS Microbiol Rev. 2005;29:795-811.

6. Hoffmeister D, Keller NP. Natural products of filamentous fungi: enzymes, genes, and their regulation. Nat Prod Rep. 2007;24:393416.

7. Kempken F, Rohlfs M. Fungal secondary metabolite biosynthesisa chemical defence strategy against antagonistic animals? Fungal Ecol. 2010;3:107-14.

8. Kunzler M. Hitting the sweet spot-glycans as targets of fungal defense effector proteins. Molecules. 2015;20:8144-67.

9. Macheleidt J, Mattern DJ, Fischer J, Netzker T, Weber J, Schroeckh V, et al. Regulation and role of fungal secondary metabolites. Annu Rev Genet. 2016;50:371-92.

10. Adnani N, Rajski SR, Bugni TS. Symbiosis-inspired approaches to antibiotic discovery. Nat Prod Rep. 2017;34:784-814.

11. Netzker T, Fischer J, Weber J, Mattern DJ, Konig CC, Valiante V, et al. Microbial communication leading to the activation of silent fungal secondary metabolite gene clusters. Front Microbiol. 2015;6:299.

12. Wiemann P, Keller NP. Strategies for mining fungal natural products. J Ind Microbiol Biotechnol. 2014;41:301-13.

13. Meldau S, Erb M, Baldwin IT. Defence on demand: mechanisms behind optimal defence patterns. Ann Bot. 2012;110:1503-14.

14. Choi HW, Klessig DF. DAMPs, MAMPs, and NAMPs in plant innate immunity. BMC Plant Biol. 2016;16:232.

15. Essig A, Hofmann D, Munch D, Gayathri S, Kunzler M, Kallio PT, et al. Copsin, a novel peptide-based fungal antibiotic interfering with the peptidoglycan synthesis. J Biol Chem. 2014;289:34953-64.

16. Stockli M, Lin CW, Sieber R, Plaza DF, Ohm RA, Kunzler M. Coprinopsis cinerea intracellular lactonases hydrolyze quorum sensing molecules of Gram-negative bacteria. Fungal Genet Biol. 2017;102:49-62.

17. Plaza DF, Lin CW, van der Velden NS, Aebi M, Kunzler M. Comparative transcriptomics of the model mushroom Coprinopsis cinerea reveals tissue-specific armories and a conserved circuitry for sexual development. BMC Genom. 2014;15:492.

18. Sabotic J, Ohm RA, Kunzler M. Entomotoxic and nematotoxic lectins and protease inhibitors from fungal fruiting bodies. Appl Microbiol Biotechnol. 2016;100:91-111.

19. Plaza DF, Schmieder SS, Lipzen A, Lindquist E, Kunzler M. Identification of a novel nematotoxic protein by challenging the model mushroom coprinopsis cinerea with a fungivorous nematode. G3. 2015;6:87-98.

20. Bleuler-Martinez S, Butschi A, Garbani M, Walti MA, Wohlschlager T, Potthoff E, et al. A lectin-mediated resistance of higher fungi against predators and parasites. Mol Ecol. 2011;20: 3056-70.

21. Doll K, Chatterjee S, Scheu S, Karlovsky P, Rohlfs M. Fungal metabolic plasticity and sexual development mediate induced resistance to arthropod fungivory. Proc Biol Sci. 2013;280:20131219.

22. Rohlfs M, Albert M, Keller NP, Kempken F. Secondary chemicals protect mould from fungivory. Biol Lett. 2007;3:523-5.

23. Deveau A, Barret M, Diedhiou AG, Leveau J, de Boer W, Martin $\mathrm{F}$, et al. Pairwise transcriptomic analysis of the interactions between the ectomycorrhizal fungus Laccaria bicolor S238N and three beneficial, neutral and antagonistic soil bacteria. Microb Ecol. 2015;69:146-59.

24. Gkarmiri K, Finlay RD, Alstrom S, Thomas E, Cubeta MA, Hogberg N. Transcriptomic changes in the plant pathogenic fungus Rhizoctonia solani AG-3 in response to the antagonistic bacteria Serratia proteamaculans and Serratia plymuthica. BMC Genom. 2015;16:630.
25. Ipcho S, Sundelin T, Erbs G, Kistler HC, Newman MA, Olsson S. Fungal innate immunity induced by bacterial Microbe-Associated Molecular Patterns (MAMPs). G3. 2016;6:1585-95.

26. Lamacchia M, Dyrka W, Breton A, Saupe SJ, Paoletti M. Overlapping podospora anserina transcriptional responses to bacterial and fungal non self indicate a multilayered innate immune response. Front Microbiol. 2016;7:471.

27. Mathioni SM, Patel N, Riddick B, Sweigard JA, Czymmek KJ, Caplan JL, et al. Transcriptomics of the rice blast fungus Magnaporthe oryzae in response to the bacterial antagonist Lysobacter enzymogenes reveals candidate fungal defense response genes. PLoS ONE. 2013;8:e76487.

28. Mela F, Fritsche K, de Boer W, van Veen JA, de Graaff LH, van den Berg M, et al. Dual transcriptional profiling of a bacterial/ fungal confrontation: Collimonas fungivorans versus Aspergillus niger. ISME J. 2011;5:1494-504.

29. Benoit I, van den Esker MH, Patyshakuliyeva A, Mattern DJ, Blei F, Zhou M, et al. Bacillus subtilis attachment to Aspergillus niger hyphae results in mutually altered metabolism. Environ Microbiol. 2015; 17:2099-113.

30. Schroeckh V, Scherlach K, Nutzmann HW, Shelest E, SchmidtHeck W, Schuemann J, et al. Intimate bacterial-fungal interaction triggers biosynthesis of archetypal polyketides in Aspergillus nidulans. Proc Natl Acad Sci USA. 2009;106:14558-63.

31. Oh DC, Kauffman CA, Jensen PR, Fenical W. Induced production of emericellamides $\mathrm{A}$ and $\mathrm{B}$ from the marine-derived fungus Emericella sp. in competing co-culture. J Nat Prod. 2007;70:515-20.

32. Ola AR, Thomy D, Lai D, Brotz-Oesterhelt H, Proksch P. Inducing secondary metabolite production by the endophytic fungus Fusarium tricinctum through coculture with Bacillus subtilis. J Nat Prod. 2013;76:2094-9.

33. Wohlkonig A, Huet J, Looze Y, Wintjens R. Structural relationships in the lysozyme superfamily: significant evidence for glycoside hydrolase signature motifs. PLoS ONE. 2010;5:e15388.

34. Swamy S, Uno I, Ishikawa T. Morphogenetic effects of mutations at the a and B incompatibility factors in Coprinus-Cinereus. J Gen Microbiol. 1984;130:3219-24.

35. Branda SS, Gonzalez-Pastor JE, Ben-Yehuda S, Losick R, Kolter R. Fruiting body formation by Bacillus subtilis. P Natl Acad Sci USA. 2001;98:11621-6.

36. Hatakeyama M, Opitz L, Russo G, Qi W, Schlapbach R, Rehrauer H. SUSHI: an exquisite recipe for fully documented, reproducible and reusable NGS data analysis. BMC Bioinforma. 2016;17:228.

37. Dobin A, Davis CA, Schlesinger F, Drenkow J, Zaleski C, Jha S, et al. STAR: ultrafast universal RNA-seq aligner. Bioinformatics. 2013;29:15-21.

38. Muraguchi H, Umezawa K, Niikura M, Yoshida M, Kozaki T, Ishii K, et al. Strand-Specific RNA-Seq Analyses of Fruiting Body Development in Coprinopsis cinerea. PLoS ONE. 2015;10: e0141586.

39. Liao Y, Smyth GK, Shi W. featureCounts: an efficient general purpose program for assigning sequence reads to genomic features. Bioinformatics. 2014;30:923-30.

40. Love MI, Huber W, Anders S. Moderated estimation of fold change and dispersion for RNA-seq data with DESeq2. Genome Biol. 2014;15:550.

41. Marchler-Bauer A, Derbyshire MK, Gonzales NR, Lu S, Chitsaz F, Geer LY, et al. CDD: NCBI's conserved domain database. Nucleic Acids Res. 2015;43:D222-6.

42. Ashburner M, Ball CA, Blake JA, Botstein D, Butler H, Cherry JM, et al. Gene ontology: tool for the unification of biology. The Gene Ontology Consortium. Nat Genet. 2000;25:25-9.

43. Robinson JT, Thorvaldsdottir H, Winckler W, Guttman M, Lander ES, Getz G, et al. Integrative genomics viewer. Nat Biotechnol. 2011;29:24-6. 
44. Petersen TN, Brunak S, von Heijne G, Nielsen H. SignalP 4.0: discriminating signal peptides from transmembrane regions. Nat Methods. 2011;8:785-6.

45. Krogh A, Larsson B, von Heijne G, Sonnhammer EL. Predicting transmembrane protein topology with a hidden Markov model: application to complete genomes. J Mol Biol. 2001;305:567-80.

46. Thompson JD, Gibson TJ, Higgins DG. Multiple sequence alignment using ClustalW and ClustalX. Curr Protoc Bioinformatics. 2002;00:2.3.1-2.3.22.

47. Franzoi M, van Heuvel Y, Thomann S, Schurch N, Kallio PT, Venier P, et al. Structural Insights into the mode of action of the peptide antibiotic copsin. Biochemistry. 2017;56:4992-5001.

48. Wu S, Letchworth GJ. High efficiency transformation by electroporation of Pichia pastoris pretreated with lithium acetate and dithiothreitol. Biotechniques. 2004;36:152-4.

49. Meskauskas A, Novak Frazer L, Moore D. Mathematical modelling of morphogenesis in fungi: a key role for curvature compensation ('autotropism') in the local curvature distribution model. New Phytol. 1999;143:387-99.

50. Kunst, F. et al. The complete genome sequence of the grampositive bacterium Bacillus subtilis. Nature 390, 249-256 (1997)

51. Droce A, Sorensen JL, Giese H, Sondergaard TE. Glass bead cultivation of fungi: combining the best of liquid and agar media. $\mathrm{J}$ Microbiol Methods. 2013;94:343-6.

52. Brandenburger E, Braga D, Kombrink A, Lackner G, Gressler J, Kunzler M, et al. Multi-genome analysis identifies functional and phylogenetic diversity of basidiomycete adenylate-forming reductases. Fungal Genet Biol. 2016;112:55-63.

53. Agger S, Lopez-Gallego F, Schmidt-Dannert C. Diversity of sesquiterpene synthases in the basidiomycete Coprinus cinereus. Mol Microbiol. 2009;72:1181-95.

54. Stajich JE, Wilke SK, Ahren D, Au CH, Birren BW, Borodovsky $\mathrm{M}$, et al. Insights into evolution of multicellular fungi from the assembled chromosomes of the mushroom Coprinopsis cinerea (Coprinus cinereus). Proc Natl Acad Sci USA. 2010;107:1188994.

55. Coleman JJ, Mylonakis E. Efflux in fungi: la piece de resistance. PLoS Pathog. 2009;5:e1000486.

56. Lo Presti L, Lanver D, Schweizer G, Tanaka S, Liang L, Tollot M, et al. Fungal effectors and plant susceptibility. Annu Rev Plant Biol. 2015;66:513-45.

57. Plett JM, Daguerre Y, Wittulsky S, Vayssieres A, Deveau A, Melton SJ, et al. Effector MiSSP7 of the mutualistic fungus Laccaria bicolor stabilizes the Populus JAZ6 protein and represses jasmonic acid (JA) responsive genes. Proc Natl Acad Sci USA. 2014;111:8299-304.

58. Sanchez-Vallet A, Mesters JR, Thomma BP. The battle for chitin recognition in plant-microbe interactions. FEMS Microbiol Rev. 2015;39:171-83

59. Baldrian P. Fungal laccases-occurrence and properties. FEMS Microbiol Rev. 2006;30:215-42.

60. Kelley LA, Mezulis S, Yates CM, Wass MN, Sternberg MJ. The Phyre2 web portal for protein modeling, prediction and analysis. Nat Protoc. 2015;10:845-58.

61. Mygind PH, Fischer RL, Schnorr KM, Hansen MT, Sonksen CP, Ludvigsen $\mathrm{S}$, et al. Plectasin is a peptide antibiotic with therapeutic potential from a saprophytic fungus. Nature. 2005;437:975-80.

62. Zhu S. Discovery of six families of fungal defensin-like peptides provides insights into origin and evolution of the CSalphabeta defensins. Mol Immunol. 2008;45:828-38.

63. Weaver LH, Matthews BW. Structure of bacteriophage T4 lysozyme refined at 1.7 A resolution. J Mol Biol. 1987;193:189-99.
64. Young R. Bacteriophage lysis: mechanism and regulation. Microbiol Rev. 1992;56:430-81.

65. Kuroki R, Weaver LH, Matthews BW. A covalent enzymesubstrate intermediate with saccharide distortion in a mutant T4 lysozyme. Science. 1993;262:2030-3.

66. Selsted ME, Martinez RJ. A simple and ultrasensitive enzymatic assay for the quantitative determination of lysozyme in the picogram range. Anal Biochem. 1980;109:67-70.

67. Bera A, Herbert S, Jakob A, Vollmer W, Gotz F. Why are pathogenic staphylococci so lysozyme resistant? The peptidoglycan O-acetyltransferase OatA is the major determinant for lysozyme resistance of Staphylococcus aureus. Mol Microbiol. 2005;55:778-87.

68. Jones JD, Dangl JL. The plant immune system. Nature. 2006;444:323-9.

69. Rovenich H, Boshoven JC, Thomma BP. Filamentous pathogen effector functions: of pathogens, hosts and microbiomes. Curr Opin Plant Biol. 2014;20:96-103.

70. Zeilinger S, Gupta VK, Dahms TE, Silva RN, Singh HB, Upadhyay RS, et al. Friends or foes? Emerging insights from fungal interactions with plants. FEMS Microbiol Rev. 2016;40: 182-207.

71. Duplessis S, Cuomo CA, Lin YC, Aerts A, Tisserant E, VeneaultFourrey $\mathrm{C}$, et al. Obligate biotrophy features unraveled by the genomic analysis of rust fungi. Proc Natl Acad Sci USA. 2011;108:9166-71.

72. Powell AJ, Conant GC, Brown DE, Carbone I, Dean RA. Altered patterns of gene duplication and differential gene gain and loss in fungal pathogens. BMC Genom. 2008;9:147.

73. Martin JF, Liras P. Evolutionary formation of gene clusters by reorganization: the meleagrin/roquefortine paradigm in different fungi. Appl Microbiol Biotechnol. 2016;100:1579-87.

74. Hurst LD, Pal C, Lercher MJ. The evolutionary dynamics of eukaryotic gene order. Nat Rev Genet. 2004;5:299-310.

75. Batada NN, Urrutia AO, Hurst LD. Chromatin remodelling is a major source of coexpression of linked genes in yeast. Trends Genet. 2007;23:480-4.

76. Oeemig JS, Lynggaard C, Knudsen DH, Hansen FT, Norgaard $\mathrm{KD}$, Schneider T, et al. Eurocin, a new fungal defensin: structure, lipid binding, and its mode of actioN. J Biol Chem. 2012;287:42361-72.

77. Wu J, Liu S, Wang H. Invasive fungi-derived defensins kill drugresistant bacterial pathogens. Peptides. 2018;99:82-91.

78. Wu Y, Gao B, Zhu S. New fungal defensin-like peptides provide evidence for fold change of proteins in evolution. Biosci Rep. 2017;37:BSR20160438.

79. Schmelcher M, Waldherr F, Loessner MJ. Listeria bacteriophage peptidoglycan hydrolases feature high thermoresistance and reveal increased activity after divalent metal cation substitution. Appl Microbiol Biotechnol. 2012;93:633-43.

80. Xu XL, Lee RT, Fang HM, Wang YM, Li R, Zou H, et al. Bacterial peptidoglycan triggers Candida albicans hyphal growth by directly activating the adenylyl cyclase Cyrlp. Cell Host Microbe. 2008;4:28-39.

81. Bertsche U, Mayer C, Gotz F, Gust AA. Peptidoglycan perception-sensing bacteria by their common envelope structure. Int J Med Microbiol. 2015;305:217-23.

82. Uehling J, Deveau A, Paoletti M. Do fungi have an innate immune response? An NLR-based comparison to plant and animal immune systems. PLoS Pathog. 2017;13:e1006578.

83. Grigoriev IV, Nikitin R, Haridas S, Kuo A, Ohm R, Otillar R, et al. MycoCosm portal: gearing up for 1000 fungal genomes. Nucleic Acids Res. 2014;42:D699-704. 